\title{
Resection frequency map after awake resective surgery for non-lesional neocortical epilepsy involving eloquent areas
}

\author{
Young-Hoon Kim • Chi Heon Kim • June Sic Kim • \\ Sang Kun Lee $\cdot$ Chun Kee Chung
}

Received: 22 February 2011 / Accepted: 15 June 2011 /Published online: 6 July 2011

(C) The Author(s) 2011. This article is published with open access at Springerlink.com

\begin{abstract}
Background The resection of eloquent areas is challenging due to postoperative neurological deficits. The purpose of this study was to assess the efficacy and risk of awake brain surgery for non-lesional epilepsy involving the eloquent areas or their adjacent areas and to advocate the generation of a resection frequency map.

Methods We enrolled 55 patients who underwent awake surgery between 1994 and 2007 for non-lesional epilepsy involving the primary sensori-motor or language areas. All patients underwent two-staged operations including subdural electrode monitoring and awake resective surgery. For each case, the preoperative and postoperative images were spatially normalized and compared on a standard atlas, and the resection map was then computed by summing up each resected area on the atlas.

Results The postoperative seizure outcome was Engel class I in 27 patients (49.1\%), II in nine (16.4\%), III in 14
\end{abstract}

Electronic supplementary material The online version of this article (doi:10.1007/s00701-011-1074-6) contains supplementary material, which is available to authorized users.

Y.-H. Kim • C. H. Kim • J. S. Kim • C. K. Chung $(\bowtie)$

Department of Neurosurgery, Seoul National

University College of Medicine,

101 Daehangno, Jongno-gu,

Seoul, Korea 110-744

e-mail: chunge@snu.ac.kr

Y.-H. Kim $•$ C. H. Kim • J. S. Kim • C. K. Chung

Department of Neurosurgery, Seoul National University Hospital,

Seoul, Korea

S. K. Lee

Department of Neurology, Seoul National University Hospital,

Seoul, Korea
(25.5\%) and IV in five (9.1\%). Ten patients (18.2\%) experienced postoperative neurological deficits including seven transient (12.7\%) and three permanent, but mild ones $(5.5 \%)$. The neurological complication rate of purely eloquent area resection was $36.8 \%(7 / 19)$. The resection frequency map computed in this study showed that the resection of eloquent areas was tolerable, with the exception of the Broca's area.

Conclusions Awake resective surgery with intraoperative brain mapping is an effective and safe treatment option for non-lesional epilepsy involving eloquent areas. The resection frequency map can show the resected area of a group as well as individuals and provide an objective measure of neurological risk.

Keywords Awake surgery. Non-lesional epilepsy. Eloquent area $\cdot$ Neurological deficit $\cdot$ Resection frequency map

\section{Introduction}

Although surgical resection of the epileptogenic zone is an effective treatment option for medically refractory localization-related epilepsy $[17,50]$, the resective surgery for the eloquent area is challenging because of the high risk of major postoperative neurological impairment $[15,30]$. Consequently, series concerning the resection of the eloquent area have presented unacceptable rates of neurological complications or been limited in the number of the patients $[3,4,10,35,36]$.

Recently, the increasing use of awake craniotomy under local anaesthesia for the management of brain tumours located in the eloquent brain revealed that this technique is associated with a low risk of new neurological impairment $[9,12,18,26,28,31,34,44,47]$. Although awake 
craniotomy, which is a useful but to some extent complicated technique, enables the maximal resection of various types of lesions (e.g. tumours and vascular malformations) without definite postoperative neurological morbidity, descriptions of awake brain surgery for non-lesional epilepsy (i.e. resection of the cortex associated with an epileptogenic zone in the eloquent cortices) are rare and limited $[3,4,10]$.

Here, we present a selected series of 55 patients with non-lesional neocortical epilepsy involving the eloquent areas or their adjacent areas that underwent awake craniotomy with cortical mapping and resection under local anaesthesia. We aimed to investigate the efficacy and complications of awake brain surgery for non-lesional epilepsy involving the eloquent areas and to introduce the resection frequency map of the eloquent areas, which was computed by summing up the resection areas.

\section{Patients and methods}

\section{Patients}

Seventy-one patients underwent awake craniotomy under local anaesthesia for the treatment of non-lesional neocortical epilepsy associated with the eloquent area or its adjacent area between December 1994 and August 2007. In this study, the eloquent area was defined as cerebral cortices including the precentral gyrus, postcentral gyrus, supplementary motor area (SMA) and Broca's area. All patients showed no definite lesions on 1.5-Tesla brain magnetic resonance imaging (MRI). Patients had an epileptogenic focus located in the eloquent area, which required preresective subdural electrodes insertion and monitoring. Preoperative and postoperative MR images with a T1-weighted three-dimensional (3D) spoiled gradient (SPGR) were not available for all cases; therefore, this study was restricted to a subgroup of 55 patients $(77.5 \%$ of the initial cohort).

The selected patients included 31 males and 24 females. The median age of the patients was 26 years (range, 1551 years), and the median duration of epilepsy was 13 years (range, 2-30 years). The mean frequency of seizures was seven per month (range, 1 to over 30 per month). The characteristics of this subgroup are summarized in Table 1. This study was approved by the Seoul National University Hospital Institutional Review Board (H0806-041-243).

Pre-resective evaluation

The preoperative evaluation protocol included a routine history taking, physical and neurological examinations, prolonged interictal electroencephalography (EEG), ictal
Table 1 Characteristics of the 55 patients recruited

\begin{tabular}{ll}
\hline Subjects & Values \\
\hline Total patients & 55 \\
Sex & \\
Male patients & $31(56.4 \%)$ \\
Female patients & $24(43.6 \%)$ \\
Median age (years) & $26(15-51)$ \\
Type of seizure & \\
Simple partial seizures & $4(7.3 \%)$ \\
Complex partial seizures (CPS) & $7(12.7 \%)$ \\
CPS \& secondary generalization & $28(50.9 \%)$ \\
Generalized tonic-clonic seizures & $16(29.1 \%)$ \\
Precedent events & \\
Developmental factors & $2(3.6 \%)$ \\
Central nervous system infection & $9(16.4 \%)$ \\
Head trauma & $16(29.1 \%)$ \\
Febrile convulsion & $6(10.9 \%)$ \\
No & $22(40.0 \%)$ \\
Median duration of epilepsy (years) & $13(2-30)$ \\
Mean frequency of seizures (/month) & $7(1$ to over 30$)$ \\
Preoperative neurological deficit & $6(10.9 \%)$ \\
\hline
\end{tabular}

video-EEG monitoring (at least three usual seizures), brain MRI, positron emission tomography (PET) and interictal and ictal single-photon emission computed tomography (SPECT). The purpose of these preoperative studies was to localize an ictal onset zone, and the concordance of these studies enabled approximation of the epileptogenic zone. Additional functional evaluation included a Wada test, neuropsychological testing, functional MRI and magnetoencephalography (MEG), which were performed in selected patients. Subdural electrodes were implanted near the presumed ictal onset zone according to video-EEG monitoring results, as no definite lesion was apparent on the MRI of all patients. All the procedures for the insertion of the subdural electrodes were carried out under general anaesthesia. After implantation of the electrodes, videoelectrocorticography monitoring was performed until at least three typical seizures occurred. After the ictal onset zone was delineated, extra-operative functional mapping (e.g. motor and language functions) was carried out via stimulation of the subdural electrodes.

Intraoperative cortical mapping

In the operating room, we paid attention to the patient's positioning, which included neck comfort, transparent facial drape for continuous monitoring and access to the airway in case emergency intubation was required. A scalp nerve block was performed to the supraorbital nerve, supratrochlear nerve, 
auriculotemporal nerve, zygomaticotemporal nerve, greater auricular nerve and occipital nerve, using local anaesthetics that included a combination of $0.5 \%$ bupivacaine and epinephrine (1:200,000). Simultaneously, the same anaesthetics were injected around the expected pin sites, where the Mayfield head fixator was applied. No intravenous sedative agent (e.g. propofol) was administered until the end of the functional mapping and resection of whole regions of the target, to avoid patient confusion.

After the dura was opened, the resection area was estimated using the previously implanted subdural electrodes. Standard cortical mapping was performed by stimulation of the brain surface with the Ojemann stimulator [6, 38]. This is a constant current generator that produces a train of biphasic square-wave pulses $(60 \mathrm{~Hz}, 1 \mathrm{~ms} /$ phase $)$ to minimize the possibility of inducing a seizure. For the localization of the eloquent areas, the stimuli were applied in increments of $1 \mathrm{~mA}$, starting at $1.5 \mathrm{~mA}$ up to a maximum of $6 \mathrm{~mA}$ for language cortices and $10 \mathrm{~mA}$ for motor cortices. A $1 \times 4$ subdural strip electrode was used both to ensure a stimulation artefact and to observe afterdischarges. Epileptologists attended the whole process and monitored the patient during the cortical stimulation. Cortical areas that yielded a response on testing were labelled with small numbered paper tickets.

\section{Awake cortical resection}

After cortical stimulation, we resected the epileptogenic zone in or adjacent to the eloquent areas, except the areas eliciting definite thumb motor or speech arrest during cortical stimulation. During the resection, the patient was asked to do continuously the particular function at risk, such as continuous conversation around the language area or movement of a limb around the motor cortex. One epileptologist was assigned for monitoring the patient's performance. We resected the epileptogenic zone as close as $1 \mathrm{~cm}$ from the speech arrest area or primary motor area especially controlling the thumb. Intraoperative stimulation to the cortex and white matter was undertaken intermittently during the resection. The resection continued until either the epileptogenic zone was removed or the onset of unexpected neurological deficits occurred. After the resection, language and motor function was tested intraoperatively.

Postoperative follow-up

All patients underwent regular follow-up at 1 month postoperatively and subsequently every $2-3$ months, which was carried out by the same neurologist and neurosurgeon. The postoperative seizure outcome was assessed according to the classification of Engel [19]. If possible, postoperative MR images were acquired three months after surgery
$(70.9 \%)$, as anatomical structures may be displaced or distorted on immediate postoperative images because of oedema or subdural fluid collection.

\section{Resection frequency map}

The preoperative and postoperative images that were available for the 55 recruited patients were used to prepare the resection frequency map of the eloquent cortices. We used T1-weighted sagittal 3D SPGR images with a thickness of $1.0 \mathrm{~mm}$. All the preoperative and postoperative images were spatially normalized using the Montreal Neurological Institute (MNI) atlas and the SPM5 software (available at http://www.fil.ion.ucl.ac.uk/spm/software/ spm5) of Matlab 7.0 (MathWorks, Natick, Mass.). All resected areas [i.e. regions of interest (ROIs)] were delineated manually on each preoperative MRI by comparison with each postoperative MRI using the MRIcro software (available at http://www.sph.sc.edu/comd/rorden/ mricro.html). These analyses were carried out by experienced neurosurgeons (Y.-H.K. and C.H.K.). In this study, the preoperative MRI was used as the template to minimize the distortion of the postoperative MRI. We generated the resection frequency map by combining all ROIs together on an atlas using Matlab 7.0. As a result, 2D axial, coronal and sagittal images and 3D volume-rendering images were obtained using the MRIcron software (available at http:// www.sph.sc.edu/comd/rorden/mricron).

\section{Results}

\section{Seizure outcome}

The postoperative seizure outcome was Engel class I in 27 patients $(49.1 \%)$, class II in nine patients $(16.4 \%)$, class III in 14 patients $(25.5 \%)$ and class IV in five patients $(9.1 \%)$. In other words, the seizure-free rate was $49.1 \%$, and the good seizure outcome (Engel classes I and II) rate was $65.5 \%$. The duration of the follow-up of our patients was over 2 years (median, 72 months; range, 6-136 months), with the exception of five cases, which included three cases that were lost at follow-up.

\section{Operative results}

Among the 55 cases, resection of the right hemisphere was performed in 25 cases, and resection of the left hemisphere in 30 cases. Only one patient displayed a right dominant hemisphere; this individual underwent resection of the right middle frontal gyrus. The remaining 54 patients, including the 30 patients who had resection of the left hemisphere, showed a left dominant hemisphere. The particular lobar 
Table 2 Lobar distribution of the 55 patients

\begin{tabular}{lllll}
\hline & Frontal & Parietal & Temporal & Multilobar \\
\hline Left & 13 & 6 & 7 & 4 \\
Right & 14 & 4 & 1 & 6 \\
\hline
\end{tabular}

distribution of the patients is described in Table 2. The frontal lobe was most often involved in 27 cases, because it includes the precentral gyrus, SMA and Broca's area. In one case involving the right temporal lobe, the epileptogenic focus was located in the uppermost portion of the supratemporal gyrus and middle temporal gyrus, which are adjacent to the area that controls the motor function of the mouth and face. The postoperative axial MR images and 3D volume-rendering images of the 55 patients were available online as supplementary images (Supplementary Figs. 1 and 2).

Thirty-five patients $(63.6 \%)$ underwent focal corticectomy, 14 patients $(25.5 \%)$ had near-total frontal lobectomy, and six patients $(10.9 \%)$ underwent lateral temporal lobectomy. Pathological examination was performed in 51 cases, which revealed the presence of cortical dysplasia in 40 cases, cortical scar in five cases, contusion in two cases, ischemia in two cases, reactive gliosis in one case and encephalomalacia in one case. In the remaining four patients, pathological examination was not requested because all the tissue was suctioned away intraoperatively. The mean operation time, i.e. from the time of induction of anaesthesia to the closure of skin, was 300 min (range, 155-450 $\mathrm{min}$ ). The mean postoperative hospital stay was 7 days (range, 3-24 days).

Postoperative neurological deficits and complications

Postoperative neurological deficits, which were the most noticeable complications in the patients after eloquent cortical resection, developed in ten patients (18.2\%). The clinical data of these ten patients are included in Table 3, 4, and 5. Among the ten patients who developed neurological deficits, seven patients $(12.7 \%)$ had transient deficits; two patients motor weakness, one patient paraesthesia, three patients motor dysphasia, and one patient sensory dysphasia. The seven

Table 3 Clinical data of the nine patients who underwent the resection of the primary sensori-motor cortices

\begin{tabular}{|c|c|c|c|c|c|c|c|}
\hline \multirow{2}{*}{ No } & \multirow{2}{*}{$\begin{array}{l}\text { Sex } \\
\text { Age }\end{array}$} & \multicolumn{4}{|c|}{ Resected area } & \multirow{2}{*}{ Postop N/D } & \multirow{2}{*}{$\mathrm{Sz}$} \\
\hline & & Side & Gyrus & Stimulation & Map & & \\
\hline 1 & $\begin{array}{l}\mathrm{M} / \\
23\end{array}$ & Rt & $\begin{array}{l}\text { IPL \& lower part of } \\
\text { pre \& post CG }\end{array}$ & Motor of face & & No deficit & $\mathrm{I}$ \\
\hline 2 & $\begin{array}{l}\mathrm{M} / \\
25\end{array}$ & $\mathrm{Lt}$ & $\begin{array}{c}\text { Lower part of pre \& } \\
\text { post } C G\end{array}$ & $\begin{array}{l}\text { Motor \& sensory } \\
\text { of face \& tongue }\end{array}$ & & $\begin{array}{l}\text { Permanent mild dysarthria } \\
\text { (Until last f/u, 7yrs) }\end{array}$ & I \\
\hline 3 & $\begin{array}{l}\text { M/ } \\
24\end{array}$ & Rt & $\begin{array}{l}\text { STG \& lower part } \\
\text { of pre \& post CG }\end{array}$ & $\begin{array}{l}\text { Motor \& sensory } \\
\text { of face \& neck }\end{array}$ & & No deficit & I \\
\hline 4 & $\begin{array}{l}\mathrm{F} / \\
30\end{array}$ & Rt & $\begin{array}{l}\text { Ant part of preCG } \\
\& \text { SFG, MFG, IFG }\end{array}$ & $\begin{array}{l}\text { Motor of shoulder } \\
\text { \& upper arm }\end{array}$ & & $\begin{array}{l}\text { Transient weakness of U/E } \\
\text { (Gr 3/5, 3days) }\end{array}$ & I \\
\hline 5 & $\begin{array}{l}\text { M/ } \\
29\end{array}$ & $\mathrm{Lt}$ & PostCG \& SPL & $\begin{array}{l}\text { Sensory of } \\
\text { arm \& hand }\end{array}$ & & No deficit & I \\
\hline 6 & $\begin{array}{l}\mathrm{M} / \\
32\end{array}$ & $\mathrm{Lt}$ & PostCG \& SPL & No function & & No deficit & III \\
\hline 7 & $\begin{array}{l}\mathrm{F} / \\
18\end{array}$ & Rt & PostCG \& IPL & Sensory of face & & No deficit & I \\
\hline 8 & $\begin{array}{l}\mathrm{M} / \\
30\end{array}$ & Rt & PostCG \& IPL & $\begin{array}{l}\text { Sensory of } \\
\text { face \& hand }\end{array}$ & & $\begin{array}{l}\text { Transient paraesthesia } \\
\text { of hand (3days) }\end{array}$ & II \\
\hline 9 & $\begin{array}{l}\mathrm{F} / \\
38\end{array}$ & $\mathrm{Lt}$ & PostCG \& SPL & No function & & No deficit & III \\
\hline
\end{tabular}

Stimulation; Intraoperative findings of stimulation in the resected target area, Postop N/D; postoperative neurological deficit, Sz; seizure outcome by Engel's classification, M; male, F; female, Rt; right, Lt; left, SFG; superior frontal gyrus, MFG; middle frontal gyrus, IFG; inferior frontal gyrus, CG; central gyrus, PreCG; precentral gyrus, PostCG; postcentral gyrus, SPL; superior parietal lobule, IPL; inferior parietal lobule, STG; superior temporal gyrus, MTG; middle temporal gyrus, ITG; inferior temporal gyrus, Gr; grade, f/u; follow up 
Table 4 Clinical data of the eight patients who underwent the resection of the SMA

\begin{tabular}{|c|c|c|c|c|c|c|c|}
\hline \multirow{2}{*}{ No } & \multirow{2}{*}{$\begin{array}{l}\text { Sex } \\
\text { Age }\end{array}$} & \multicolumn{4}{|c|}{ Resected area } & \multirow{2}{*}{ Postop N/D } & \multirow{2}{*}{$\mathrm{Sz}$} \\
\hline & & Side & Gyrus & Stimulation & Map & & \\
\hline 10 & $\begin{array}{l}\mathrm{M} / \\
36\end{array}$ & $\mathrm{Lt}$ & $\begin{array}{l}\text { Post part of } \\
\text { SFG \& MFG }\end{array}$ & No function & & $\begin{array}{l}\text { Permanent coordination } \\
\text { disturbance of hand } \\
\text { (until last f/u, } 10 \text { years) }\end{array}$ & I \\
\hline 11 & $\begin{array}{l}\mathrm{F} / \\
27\end{array}$ & $\mathrm{Lt}$ & $\begin{array}{l}\text { Whole frontal lobe } \\
\text { except preCG \& } \\
\text { the Broca's area }\end{array}$ & "No function & & No deficit & III \\
\hline 12 & $\begin{array}{l}\mathrm{M} / \\
24\end{array}$ & Rt & $\begin{array}{l}\text { Whole frontal lobe } \\
\text { except preCG }\end{array}$ & ${ }^{\dagger}$ No function & & No deficit & I \\
\hline 13 & $\begin{array}{l}\mathrm{F} / \\
34\end{array}$ & Rt & $\begin{array}{l}\text { Post part of } \\
\text { SFG \& MFG }\end{array}$ & No function & & No deficit & I \\
\hline 14 & $\begin{array}{l}\mathrm{M} / \\
26\end{array}$ & Rt & $\begin{array}{l}\text { Post part of } \\
\text { SFG \& MFG }\end{array}$ & ${ }^{\S}$ Failed & & No deficit & I \\
\hline 15 & $\begin{array}{l}\mathrm{F} / \\
17\end{array}$ & Rt & $\begin{array}{l}\text { Post part of } \\
\text { SFG \& MFG }\end{array}$ & No function & & No deficit & I \\
\hline 16 & $\begin{array}{l}\mathrm{M} / \\
23\end{array}$ & Rt & $\begin{array}{l}\text { Whole frontal lobe } \\
\text { except preCG }\end{array}$ & ${ }^{\dagger}$ No function & & No deficit & II \\
\hline 17 & $\begin{array}{l}\mathrm{M} / \\
30\end{array}$ & Rt & Post part of SFG & No function & & $\begin{array}{l}\text { Transient weakness of } \mathrm{L} / \mathrm{E} \\
\text { (Gr 3/5, } 6 \text { months) }\end{array}$ & III \\
\hline
\end{tabular}

* The hand motor area located just posterior and the language area just inferior to the margin of resection.

$\dagger$ The hand motor area located just posterior to the margin of resection.

$\S$ Intraoperative functional monitoring was failed due to poor cooperation of the patient.

SMA; supplementary motor area, Stimulation; Intraoperative findings of stimulation in the resected target area, Postop N/D; postoperative neurological deficit, Sz; seizure outcome by Engel's classification, M; male, F; female, Rt; right, Lt; left, SFG; superior frontal gyrus, MFG; middle frontal gyrus, IFG; inferior frontal gyrus, CG; central gyrus, PreCG; precentral gyrus, PostCG; postcentral gyrus, SPL; superior parietal lobule, IPL; inferior parietal lobule, STG; superior temporal gyrus, MTG; middle temporal gyrus, ITG; inferior temporal gyrus, Gr; grade, f/u; follow up

patients with transient morbidities recovered fully from the deficits within several months (mean, 1 month; range, 3 days to 6 months). Three patients (5.5\%) presented with permanent deficits, which included one coordination disturbance of hand movement, one mild dysarthria and one mild motor dysphasia without difficulty in normal life. There was neither major neurological deficit nor mortality among all the patients.

In five cases $(9.1 \%)$, we could not complete the continuous neurological monitoring because of poor patient cooperation; two patients $(3.6 \%)$ had postoperative infections that required the removal of the infected bone flap, and 2 two patients $(3.6 \%)$ underwent additional surgery to remove postoperative hematomas.

\section{Resection frequency map}

Figure 1 shows the bilateral and superior 3D volumerendering images of the resection frequency map. The anatomically eloquent cortices, which include the precentral gyrus, postcentral gyrus, SMA, Broca's area (i.e. the pars triangularis and opercularis of the dominant hemisphere), and Wernicke's area (i.e. the posterior part of the superior temporal gyrus of the dominant hemisphere) were identified easily in these images. By showing surface views of the hemisphere, the $3 \mathrm{D}$ volume-rendering images enabled us to discriminate definitively between the resected area and the unresected area.

The resection map of individual patients showed the resected area objectively in terms of a cortical surface (resection maps in Tables 3, 4 and 5). In this series, three patients underwent the excision of the precentral and postcentral gyri, one patient the precentral gyrus and the SMA, five patients the postcentral gyrus, two patients the pars triangularis of the dominant hemisphere, eight patients the SMA, and remaining 36 patients their adjacent gyri. The specific gyral distribution and neurological outcome of the 55 patients were summarized in Table 6 . Among eight patients who underwent the resection of Broca's area or its adjacent gyri, four patients $(50 \%)$ suffered from postoperative motor dysphasia in spite of preserving language functions intraoperatively. On the other hand, the patients 
Table 5 Clinical data of the eight patients who underwent the resection of the Broca's area or its adjacent gyrus and remaining one patient who experienced postoperative Nneurological deficit; case 11 has already been described in Table 4

\begin{tabular}{|c|c|c|c|c|c|c|c|}
\hline \multirow{2}{*}{ No } & \multirow{2}{*}{$\begin{array}{l}\text { Sex } \\
\text { Age }\end{array}$} & \multicolumn{4}{|c|}{ Resected area } & \multirow{2}{*}{ Postop N/D } & \multirow{2}{*}{$\mathrm{Sz}$} \\
\hline & & Side & Gyrus & Stimulation & Map & & \\
\hline 11 & $\begin{array}{l}\mathrm{F} / \\
27\end{array}$ & $\mathrm{Lt}$ & $\begin{array}{l}\text { Whole frontal lobe } \\
\text { except preCG \& } \\
\text { the Broca's area }\end{array}$ & No function & & No deficit & III \\
\hline 18 & $\begin{array}{l}\mathrm{M} / \\
31\end{array}$ & $\mathrm{Lt}$ & SFG \& MFG & No function & & No deficit & I \\
\hline 19 & $\begin{array}{l}\text { M/ } \\
19\end{array}$ & $\mathrm{Lt}$ & $\begin{array}{l}\text { Pars triangularis \& } \\
\text { combined ATL }\end{array}$ & ${ }^{\dagger}$ No function & & $\begin{array}{l}\text { Transient motor dysphasia } \\
\qquad(1 \text { month })\end{array}$ & II \\
\hline 20 & $\begin{array}{l}\mathrm{F} / \\
24\end{array}$ & $\mathrm{Lt}$ & $\begin{array}{l}\text { Ant part of SFG, } \\
\text { MFG, \& IFG }\end{array}$ & No function & & $\begin{array}{l}\text { Transient motor dysphasia } \\
\qquad \text { (8 days) }\end{array}$ & I \\
\hline 21 & $\begin{array}{l}\text { M/ } \\
26\end{array}$ & $\mathrm{Lt}$ & $\begin{array}{l}\text { Pars orbitalis \& } \\
\text { triangularis }\end{array}$ & ${ }^{\dagger}$ No function & & $\begin{array}{l}\text { Permanent motor dysphasia } \\
\quad \text { (until last f/u, 8yrs) }\end{array}$ & II \\
\hline 22 & $\begin{array}{l}\mathrm{M} / \\
28\end{array}$ & $\mathrm{Lt}$ & $\begin{array}{l}\text { Post part of } \\
\text { SFG \& MFG }\end{array}$ & ${ }^{\S}$ No function & & $\begin{array}{l}\text { Transient motor dysphasia } \\
\text { (5days) }\end{array}$ & III \\
\hline 23 & $\begin{array}{l}\mathrm{F} / \\
28\end{array}$ & $\mathrm{Lt}$ & $\begin{array}{l}\text { Ant part of } \\
\text { SFG \& MFG }\end{array}$ & No function & & No deficit & IV \\
\hline 24 & $\begin{array}{l}\mathrm{M} / \\
25\end{array}$ & $\mathrm{Lt}$ & Post part of MFG & ${ }^{\S}$ No function & & No deficit & II \\
\hline 25 & $\begin{array}{l}\mathrm{F} / \\
28\end{array}$ & $\mathrm{Lt}$ & MTG \& ITG & ${ }^{* *}$ Failed & & $\begin{array}{l}\text { Transient sensory dysphasia } \\
\text { (1 month) }\end{array}$ & I \\
\hline
\end{tabular}

* The hand motor area located just posterior and the language area just inferior to the margin of resection.

$\uparrow$ The language area located just posterior to the margin of resection.

$\S$ The language area located just inferior to the margin of resection.

** Intraoperative functional monitoring was failed due to poor cooperation of the patient.

Stimulation; Intraoperative findings of stimulation in the resected target area, Postop N/D; postoperative neurological deficit, Sz; seizure outcome by Engel's classification, M; male, F; female, Rt; right, Lt; left, SFG; superior frontal gyrus, MFG; middle frontal gyrus, IFG; inferior frontal gyrus, CG; central gyrus, PreCG; precentral gyrus, PostCG; postcentral gyrus, SPL; superior parietal lobule, IPL; inferior parietal lobule, STG; superior temporal gyrus, MTG; middle temporal gyrus, ITG; inferior temporal gyrus, Gr; grade, f/u; follow up

who underwent the excision of the adjacent gyri to the primary sensori-motor cortices presented with no postoperative neurological deficit. The neurological risk in the resection of the Broca's area or its adjacent areas was significantly higher than that of other areas (odds ratio, $6.833 ; 95 \%$ confidence interval $1.340-34.853 ; P=0.029$ ).

\section{Discussion}

Epilepsy control via awake resective surgery

The surgical intervention for non-lesional epilepsy involving eloquent areas has been challenging due to difficulty in delineating the epileptogenic zone and neurological risk. Therefore, many authors advocate a treatment for non- lesional epilepsy involving the eloquent cortices that uses a combination of surgical procedures, multiple subpial transection (MST) and resection [16, 23, 43]. MST theoretically disrupts the horizontal connections between adjacent gyri via the placement of parallel cuts $5 \mathrm{~mm}$ apart in the eloquent cortex [32]. It results in the interruption of the recruitment of the neural tissue necessary to produce a seizure, thus preventing damage to the eloquent cortices and minimizing the risk of development of neurological deficits. Actually MST can be considered as an alternative surgical option for incomplete epileptogenic zone resection. Recent data, however, revealed that MST has a relatively high relapse rate and another simple partial seizure risk $[33,46]$. In this series, in which we used resection exclusively, without MST, $49.1 \%$ of the patients experienced a postoperative seizure-free state; moreover, we observed a decrease in seizure frequency and intensity of 

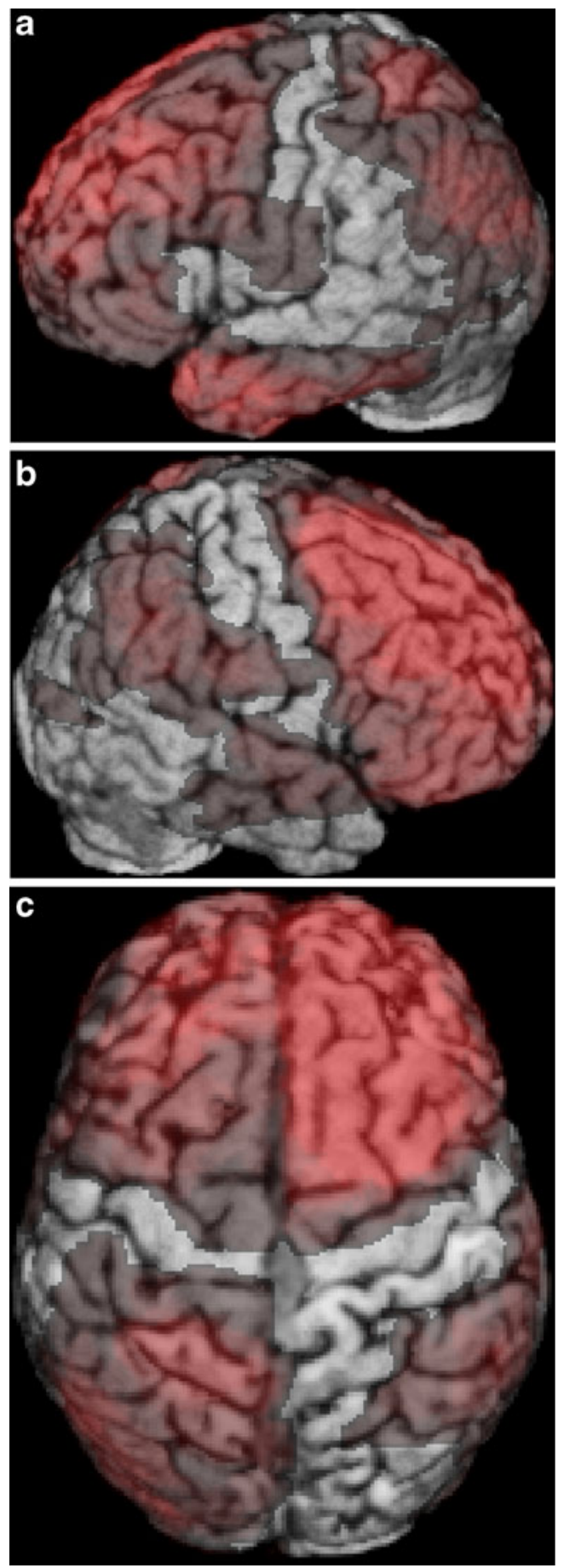

Fig. 1 Resection frequency map of the eloquent cortices (3D volumerendering images). The red-coloured areas depict the resected areas, from the surface to a $4 \mathrm{~mm}$ depth. a In the left hemisphere, most areas were resected, with the exception of the pars opercularis, the upper part of the precentral gyrus and the transverse temporal gyrus. b In the right hemisphere, most areas of the frontal lobe, the parietal lobe and the upper part of the temporal lobe were resected, with the exception of the upper part of the central lobule. c The superior view showed that both supplementary motor areas were resected totally

$90.9 \%$. These results are excellent compared with previously reported results that did not involve the eloquent cortices [11,
24, 45]. We reported the largest (and first) successful series of awake resective surgery for non-lesional epilepsy induced from the eloquent areas or their adjacent areas.

Neurological efficacy of awake brain surgery

Previously, several authors reported the possibility of, and the risks associated with, resection of the primary sensori-motor area (i.e. the central lobule or the rolandic cortex) $[35,36]$. Interestingly, studies pertaining to surgery in a particular region of the central lobule have been reported. Rasmussen [39] reported that resection of the proximal limb region is better tolerated than resection of the distal limb area. Lehman et al. [27] reported that unilateral excision of the lower central lobule, which controls the face area, is not associated with significant neurological impairment because of the bilateral cortical representation of the face. Recent reports showed that the resection of the rolandic cortices for treatment of medically intractable rolandic cortical epilepsy was effective for controlling of seizures and safe in terms of major neurological morbidities in child patients [3, 4].

In this study, four patients underwent the resection of the primary motor cortex (Table 3 ). The resection maps in Table 3 clearly show the specific region of the central lobule that was resected. Three patients underwent resection of the lower part of the precentral gyrus, which corresponds to the face and tongue motor area, and only one patient developed a permanent but mild dysarthria without difficulty in normal conversation (case 2 in Table 3). The remaining one patient underwent the resection of the limited anterior part of the precentral gyrus, which corresponds to the contralateral shoulder and upper arm motor function, and experienced transient upper extremity weakness with a full recovery 3 days after the operation (case 4 in Table 3). These results demonstrated that face or proximal limb area was relatively tolerable to post-resection neurological risk [27, 39].

A number of authors have reported an acceptable outcome after resection of the postcentral gyrus [1, 10, 25, 37]. Although the complete resection of the somatosensory cortex or of the area that controls the definite sensory function may result in permanent neurological deficits, the partial resection of these areas would only yield partial deficits, with a good potential for recovery. Only one out of the five patients who underwent the resection of the postcentral gyrus developed transient paraesthesia of contralateral hand; this patient had a full recovery (case 8 in Table 3). Two patients had excision of arm and face sensory areas without any sensory impairment (cases 5 and 7 in Table 3). No definite sensory function was detected in the resected area of the postcentral gyrus during the intraoperative functional monitoring of the remaining 2 patients (cases 6 and 9 in Table 3). These may result from the enhanced cortical plasticity present in epilepsy patients [21, $25]$. Actually most of cases in the current series corresponded 
Table 6 Gyral distribution of the resected area and neurological outcome in 55 patients

$N / D$ neurological deficits, pre $C G$ precentral gyrus, postCG postcentral gyrus, SMA supplementary motor area

a Corresponding to the pars triangularis of the dominant hemisphere

b Including the patient who underwent both SMA and the adjacent gyrus to the Broca's area (case 11 in Tables 4 and 5)

\begin{tabular}{llll}
\hline Resected gyrus & Cases & Permanent N/D & Transient N/D \\
\hline PreCG \& postCG & 3 & 1 (case 2 in Table 3) & 0 \\
PreCG \& SMA & 1 & 0 & 1 (case 4 in Table 3) \\
PostCG & 5 & 0 & 1 (case 8 in Table 3) \\
SMA & 8 & 1 (case 10 in Table 4) & 1 (case 17 in Table 4) \\
Broca's area ${ }^{\text {a }}$ & 2 & 1 (case 21 in Table 5) & 1 (case 19 in Table 5) \\
Adjacent area to PreCG & 13 & 0 & 0 \\
Adjacent area to PostCG & 5 & 0 & 0 \\
Adjacent area to Broca's area & $6^{\mathrm{b}}$ & 0 & 2 (cases 20 \& 22 in Table 5) \\
Adjacent area to Wernicke's area & 13 & 0 & 1 (case 25 in Table 5) \\
Total & $55^{\mathrm{b}}$ & 3 & 7 \\
\hline
\end{tabular}

with cortical dysplasia, and functional reorganization and neural plasticity were the significant mechanisms enabling the eloquent area resections in this pathology [22].

It is well accepted that the removal of the unilateral SMA can be accomplished without significant permanent deficits, even though the SMA controls important functions, which include initiation of motor activity and speech [51]. However, it is also well known that the removal of the SMA can cause transient neurological deficits, which include motor weakness or speech disturbance $[2,20,41,48,51]$. In the present study, eight patients underwent removal of the unilateral SMA (Table 4). Among these patients, two patients exhibited transient neurological morbidities including coordination disturbance of hand and motor weakness of contralateral leg (cases 10 and 17 in Table 4). Several factors, including the degree of resection of the SMA, injury of the cingulate gyrus and the nature of disease, could influence the degree of the neurological deficits after the removal of the SMA [2, 42, 51].

Studies on the excision of the language cortex without definite lesion are extremely rare and limited. A few reports describe the resection of the Broca's area with definite lesion (e.g. brain tumour) $[5,13]$. In the present study, two patients in the cohort underwent resection of the pars triangularis of the dominant hemisphere as a part of the Broca's area (cases 19 and 21 in Table 5), which can be delineated using anatomical and MRI landmarks [38], and six patients that of its adjacent cortex (cases 11, 18, 20, 22, 23, and 24 in Table 5). The expressive language centres of the all the patients were preserved intraoperatively. Among them, four patients $(50 \%)$, however, experienced the neurological deficits, including one permanent but mild motor dysphasia and three transient ones (cases 21, 19, 20, and 22 in Table 5). There was no case of the Wernicke's area resection in our series (Table 6). Actually the estimated receptive language areas by intraoperative monitoring in some cases were located irregularly and more anteriorly compared to conventionally known Wernicke's area [7, 14].

Therefore, our results showed that the resection of the Broca's area is more prone to result in neurological deficits than the resection of any other brain area. Therefore, the pars triangularis and opercularis of the dominant hemisphere, which can be delineated as a part of the Broca's area using anatomical and MRI landmarks [38], should not be excised carelessly, even if no definite function is detected in these two areas. However, the resections of the primary sensori-motor cortex or its adjacent area were neurologically tolerable, if the intraoperative monitoring of the motor function is done completely and thumb motor area is preserved. Consequently, pre-operative stimulations via subdural grids provided the spatial outline between the ictal onset zone and the functional area and peri-operative stimulation enabled to delineate the definite resection margin. Awake intraoperative monitoring was necessary to discriminate pure functional area from non-functional area and to avoid unexpected neurological risk.

\section{Resection frequency map of the eloquent cortices}

In this study, spatial normalization was used to integrate several individual imaging data of the 55 patients who underwent resection of the eloquent cortices. The spatial normalization of brain images, which included MRI, PET and SPECT, has been used mainly to infer brain function [8, 29]. There was no problem in the spatial normalization of non-distorted preoperative images. In contrast, the spatial normalization of postoperative images was controversial because of the mechanical displacement of the resected brain areas. Therefore, in this work, the delineation of the resected area of all cases was performed manually on the spatially normalized preoperative images by experienced neurosurgeons (Y.-H.K. and C.H.K.).

There are some significant advantages to the generation of the resection frequency map of the eloquent cortices presented here. Firstly, the resection frequency map gave objectivity to the results of the resective operation series. Consequently we could present the postoperative neurological results by functional categories, motor, sensory, Broca's and Wernicke's area. Secondly, 55 individual data regarding awake 
cortical resection of the eloquent cortices were integrated on the spatially normalized template. The resected area of the eloquent cortices could be delineated at a glance in this map. In particular, 3D volume-rendering images provided useful information for the treatment of epilepsy, as information from the cortex, (i.e. the surface of the brain) is more important than information from deeper structures (e.g. white matter). Thirdly, the resection frequency map can be used by neurosurgeons for the planning and performance of awake brain surgery of the eloquent cortex. Finally, the resection frequency map can be used in the future to verify the accuracy and error of preoperative functional studies, such as functional MRI, diffusion tensor MRI, PET, SPECT and MEG. The most accurate way to infer the function of particular brain regions is to excise these areas.

There are some limitations to this resection frequency map of the eloquent cortices. Firstly, the value of this map is not proportional; rather, this approach has additive value. For example, the resection of the area that was excised 11 times in this study does not mean that this area can be resected at a rate of $20.0 \%(11 / 55)$; rather, it merely means that this area was resected 11 times in the past. In the same manner, the presence of areas that were unresected does not imply that these areas should not be resected; it is merely a statement that the area was not resected in the current study. Secondly, the meaning of the disease category of this map should not be extrapolated to tumours, vascular malformations and other lesional epilepsy forms, as there are clear differences in the mechanisms of functional reorganization among these diseases $[10,40,49]$. The data used to generate this map were restricted to non-lesional epilepsy. Moreover, the causative lesions in epilepsy might be missed by 1.5 -Tesla MRIs, especially performed in the early $1990 \mathrm{~s}$. Finally, this resection frequency map is subject to inherent technical difficulties that arise from the manual delineation of each resected area on an atlas and from the integration of each individual datum. To minimize these difficulties, experienced neurosurgeons (Y.-H.K. and C.H.K.) delineated all the ROIs manually and an additional experienced neurosurgeon (C.K.C.) examined each individual case in detail.

\section{Conclusions}

In conclusion, awake resective surgery under local anaesthesia with intraoperative functional mapping is an effective and safe treatment option for non-lesional neocortical epilepsy involving the eloquent areas or their adjacent areas. The resection frequency map showed that resection of the anatomically eloquent areas except for the Broca's area was tolerable after complete intraoperative functional monitoring. The resection frequency map can show the resected area of a group as well as individuals and provide an objective measure of neurological risk.

Acknowledgements This study was supported by a grant of the Korea Healthcare Technology R \& D Project, Ministry for Health, Welfare and Family Affairs, Republic of Korea (A084368). This research was jointly supported by grants from the Brain Research Center of the 21st Century Frontier Research Program (2011K000284) funded by the Ministry of Education, Science and Technology, the Republic of Korea.

\section{Conflicts of interest None.}

Open Access This article is distributed under the terms of the Creative Commons Attribution Noncommercial License which permits any noncommercial use, distribution, and reproduction in any medium, provided the original author(s) and source are credited.

\section{References}

1. Asano E, Ishikawa S, Otsuki T, Nakasato N, Yoshimoto T (1999) Surgical treatment of intractable epilepsy originating from the primary sensory area of the hand - case report. Neurol Med Chir (Tokyo) 39:246-250

2. Bannur U, Rajshekhar V (2000) Post operative supplementary motor area syndrome: clinical features and outcome. $\mathrm{Br} \mathrm{J}$ Neurosurg 14:204-210

3. Behdad A, Limbrick DD Jr, Bertrand ME, Smyth MD (2009) Epilepsy surgery in children with seizures arising from the rolandic cortex. Epilepsia 50:1450-1461

4. Benifla M, Sala F Jr, Jane J, Otsubo H, Ochi A, Drake J, Weiss S, Donner E, Fujimoto A, Holowka S, Widjaja E, Snead OC 3rd, Smith ML, Tamber MS, Rutka JT (2009) Neurosurgical management of intractable rolandic epilepsy in children: role of resection in eloquent cortex. Clinical article J Neurosurg Pediatr 4:199-216

5. Benzagmout M, Gatignol P, Duffau H (2007) Resection of World Health Organization Grade II gliomas involving Broca's area: methodological and functional considerations. Neurosurgery 61:741-752, discussion 752-743

6. Berger MS, Kincaid J, Ojemann GA, Lettich E (1989) Brain mapping techniques to maximize resection, safety, and seizure control in children with brain tumors. Neurosurgery 25:786-792

7. Bogen JE, Bogen GM (1976) Wernicke's region-Where is it? Ann N Y Acad Sci 280:834-843

8. Brett M, Johnsrude IS, Owen AM (2002) The problem of functional localization in the human brain. Nat Rev Neurosci 3:243-249

9. Bulsara KR, Johnson J, Villavicencio AT (2005) Improvements in brain tumor surgery: the modern history of awake craniotomies. Neurosurg Focus 18:e5

10. Cohen-Gadol AA, Britton JW, Collignon FP, Bates LM, Cascino GD, Meyer FB (2003) Nonlesional central lobule seizures: use of awake cortical mapping and subdural grid monitoring for resection of seizure focus. J Neurosurg 98:1255-1262

11. Cukiert A, Buratini JA, Machado E, Sousa A, Vieira JO, Argentoni M, Forster C, Baldauf C (2001) Results of surgery in patients with refractory extratemporal epilepsy with normal or nonlocalizing magnetic resonance findings investigated with subdural grids. Epilepsia 42:889-894

12. Danks RA, Aglio LS, Gugino LD, Black PM (2000) Craniotomy under local anesthesia and monitored conscious sedation for the resection of tumors involving eloquent cortex. J Neurooncol 49:131-139 
13. de Amorim RL, de Almeida AN, de Aguiar PH, Fonoff ET, Itshak S, Fuentes D, Teixeira MJ (2008) Cortical stimulation of language fields under local anesthesia: optimizing removal of brain lesions adjacent to speech areas. Arq Neuropsiquiatr 66:534-538

14. Demonet JF, Chollet F, Ramsay S, Cardebat D, Nespoulous JL, Wise R, Rascol A, Frackowiak R (1992) The anatomy of phonological and semantic processing in normal subjects. Brain 115(Pt 6):1753-1768

15. Devaux B, Chassoux F, Landre E, Turak B, Abou-Salma Z, Mann M, Pallud J, Baudouin-Chial S, Varlet P, Rodrigo S, Nataf F, Roux FX (2008) Surgical resections in functional areas: report of 89 cases. Neurochirurgie 54:409-417

16. Devinsky O, Romanelli P, Orbach D, Pacia S, Doyle W (2003) Surgical treatment of multifocal epilepsy involving eloquent cortex. Epilepsia 44:718-723

17. Dreifuss FE (1987) Goals of surgery for epilepsy. In: Engel J Jr (ed) In: Surgical treatment of the epilepsies. Raven Press, New York, pp 31-50

18. Duffau H, Capelle L, Denvil D, Sichez N, Gatignol P, Taillandier L, Lopes M, Mitchell MC, Roche S, Muller JC, Bitar A, Sichez JP, van Effenterre R (2003) Usefulness of intraoperative electrical subcortical mapping during surgery for low-grade gliomas located within eloquent brain regions: functional results in a consecutive series of 103 patients. J Neurosurg 98:764-778

19. Engel J, Van Ness PC, Rasmussen TB (1993) Outcome with respect to epileptic seizures. In: Engel J (ed) In: Surgical treatment of the epilepsies, 2nd edn. Raven Press, New York, pp 609-621

20. Fukaya C, Katayama Y, Kobayashi K, Kasai M, Oshima H, Yamamoto T (2003) Impairment of motor function after frontal lobe resection with preservation of the primary motor cortex. Acta Neurochir Suppl 87:71-74

21. Graveline CJ, Mikulis DJ, Crawley AP, Hwang PA (1998) Regionalized sensorimotor plasticity after hemispherectomy fMRI evaluation. Pediatr Neurol 19:337-342

22. Guerrini R, Barba C (2010) Malformations of cortical development and aberrant cortical networks: epileptogenesis and functional organization. J Clin Neurophysiol 27:372-379

23. Hufnagel A, Zentner J, Fernandez G, Wolf HK, Schramm J, Elger CE (1997) Multiple subpial transection for control of epileptic seizures: effectiveness and safety. Epilepsia 38:678688

24. Jayakar P, Dunoyer C, Dean P, Ragheb J, Resnick T, Morrison G, Bhatia S, Duchowny M (2008) Epilepsy surgery in patients with normal or nonfocal MRI scans: integrative strategies offer longterm seizure relief. Epilepsia 49:758-764

25. Koubeissi MZ, Maciunas RJ, Tanner A, Luders HO (2008) Medically intractable seizures originating from the primary somatosensory hand area. Epileptic Disord 10:339-348

26. Larkin M (1999) Neurosurgeons wake up to awake-brain surgery. Lancet 353:1772

27. Lehman R, Andermann F, Olivier A, Tandon PN, Quesney LF, Rasmussen TB (1994) Seizures with onset in the sensorimotor face area: clinical patterns and results of surgical treatment in 20 patients. Epilepsia 35:1117-1124

28. Low D, Ng I, Ng WH (2007) Awake craniotomy under local anaesthesia and monitored conscious sedation for resection of brain tumours in eloquent cortex-outcomes in 20 patients. Ann Acad Med Singapore 36:326-331

29. Mandonnet E, Jbabdi S, Taillandier L, Galanaud D, Benali H, Capelle L, Duffau H (2007) Preoperative estimation of residual volume for WHO grade II glioma resected with intraoperative functional mapping. Neuro Oncol 9:63-69

30. Marnet D, Devaux B, Chassoux F, Landre E, Mann M, Turak B, Rodrigo S, Varlet P, Daumas-Duport C (2008) Surgical resection of focal cortical dysplasias in the central region. Neurochirurgie 54:399-408

31. Meyer FB, Bates LM, Goerss SJ, Friedman JA, Windschitl WL, Duffy JR, Perkins WJ, O'Neill BP (2001) Awake craniotomy for aggressive resection of primary gliomas located in eloquent brain. Mayo Clin Proc 76:677-687

32. Morrell F, Whisler WW, Bleck TP (1989) Multiple subpial transection: a new approach to the surgical treatment of focal epilepsy. J Neurosurg 70:231-239

33. Orbach D, Romanelli P, Devinsky O, Doyle W (2001) Late seizure recurrence after multiple subpial transections. Epilepsia 42:13161319

34. Otani N, Bjeljac M, Muroi C, Weniger D, Khan N, Wieser HG, Curcic M, Yonekawa Y (2005) Awake surgery for glioma resection in eloquent areas-Zurich's experience and review. Neurol Med Chir (Tokyo) 45:501-510, discussion 510-501

35. Penfield W, Rasmussen T (1950) The cerebral cortex of man: a clinical study of localization of function. McMillan, New York, In

36. Pilcher C, Meacham WR, Holbrook TJ (1947) Partial excision of the motor cortex in treatment of Jacksonian convulsions. Results of forty one cases Arch Surg 54:633-643

37. Pondal-Sordo M, Diosy D, Tellez-Zenteno JF, Girvin JP, Wiebe S (2006) Epilepsy surgery involving the sensory-motor cortex. Brain 129:3307-3314

38. Quinones-Hinojosa A, Ojemann SG, Sanai N, Dillon WP, Berger MS (2003) Preoperative correlation of intraoperative cortical mapping with magnetic resonance imaging landmarks to predict localization of the Broca area. J Neurosurg 99:311318

39. Rasmussen T (1975) Surgery for epilepsy arising in regions other than the temporal and frontal lobes. Adv Neurol 8:207226

40. Robles SG, Gatignol P, Lehericy S, Duffau H (2008) Long-term brain plasticity allowing a multistage surgical approach to World Health Organization Grade II gliomas in eloquent areas. J Neurosurg 109:615-624

41. Russell SM, Kelly PJ (2003) Incidence and clinical evolution of postoperative deficits after volumetric stereotactic resection of glial neoplasms involving the supplementary motor area. Neurosurgery 52:506-516, discussiom 515-506

42. Russell SM, Kelly PJ (2007) Incidence and clinical evolution of postoperative deficits after volumetric stereotactic resection of glial neoplasms involving the supplementary motor area. Neurosurgery 61:358-367, discussion 367-358

43. Sawhney IM, Robertson IJ, Polkey CE, Binnie CD, Elwes RD (1995) Multiple subpial transection: a review of 21 cases. J Neurol Neurosurg Psychiatry 58:344-349

44. Serletis D, Bernstein M (2007) Prospective study of awake craniotomy used routinely and nonselectively for supratentorial tumors. J Neurosurg 107:1-6

45. Siegel AM, Jobst BC, Thadani VM, Rhodes CH, Lewis PJ, Roberts DW, Williamson PD (2001) Medically intractable, localization-related epilepsy with normal MRI: presurgical evaluation and surgical outcome in 43 patients. Epilepsia 42:883-888

46. Spencer SS, Schramm J, Wyler A, O'Connor M, Orbach D, Krauss G, Sperling M, Devinsky O, Elger C, Lesser R, Mulligan L, Westerveld M (2002) Multiple subpial transection for intractable partial epilepsy: an international meta-analysis. Epilepsia 43:141-145

47. Taylor MD, Bernstein M (1999) Awake craniotomy with brain mapping as the routine surgical approach to treating patients with supratentorial intraaxial tumors: a prospective trial of 200 cases. J Neurosurg 90:35-41

48. Ulu MO, Tanriover N, Ozlen F, Sanus GZ, Tanriverdi T, Ozkara C, Uzan M (2008) Surgical treatment of lesions involving the 
supplementary motor area: clinical results of 12 patients. Turk Neurosurg 18:286-293

49. Vitali P, Minati L, D'Incerti L, Maccagnano E, Mavilio N, Capello D, Dylgjeri S, Rodriguez G, Franceschetti S, Spreafico R, Villani F (2008) Functional MRI in malformations of cortical development: activation of dysplastic tissue and functional reorganization. J Neuroimaging 18:296-305
50. Wiebe S, Blume WT, Girvin JP, Eliasziw M (2001) A randomized, controlled trial of surgery for temporal-lobe epilepsy. N Engl J Med 345:311-318

51. Zentner J, Hufnagel A, Pechstein U, Wolf HK, Schramm J (1996) Functional results after resective procedures involving the supplementary motor area. J Neurosurg 85:542549 